\title{
Modeling of integral-type Stirling refrigerator using system dynamics approach
}

\author{
B.J. Huang *, H.Y. Chen \\ Department of Mechanical Engineering, National Taiwan University, Taipei 106, Taiwan
}

Received 4 May 1998; received in revised form and accepted 6 December 1999

\begin{abstract}
A modeling of the integral-type Stirling refrigerator (ITSR) using a system dynamics approach is developed in the present study. The system dynamics models are derived to describe the input/output relation of each component of an ITSR. Connecting the equivalent circuits of the components together, we obtain a flow network diagram and derive a transfer function to represent system dynamics behavior of an ITSR. The performance analysis of an ITSR is then easily carried out by use of the transfer function with sinusoidal signal assumption. The performance calculation for a test refrigerator has shown that the analysis is accurate. An empirical correlation for a correction coefficient $r$ in the expansion space was also derived for better results. The present study has demonstrated how a linear system theory or system dynamics approach can be applied to the design of an ITSR. (C) 2000 Elsevier Science Ltd and IIR. All rights reserved.
\end{abstract}

\section{Modélisation d'un réfrigérateur Stirling de type intégré à l'aide d'une approche par dynamique du système}

\begin{abstract}
Résumé
Mots clés: Cryoréfrigérateur ; Stirling ; Conception ; Modélisation

* Corresponding author. Tel.: + 886-2-2363-4790; fax: + 886-2-2364-0549.

E-mail address: bjhuang@tpts6.seed.net.tw (B.J. Huang).
\end{abstract}

Dans cette étude, on a effectué la modélisation d'un réfrigérateur Stirling de type intégré (ITSR) à l'aide d'une approche par dynamique du système. Les modèles de la dynamique du système sont développés afin de décrire la relation entrée/sortie de chaque composant d'un ITSR. En raccordant les circuits de composants, on obtient un diagramme pour l'écoulement en réseau avant de dériver une fonction de transfert qui représente le comportement dynamique du système d'un ITSR. L'analyse de la performance d'un ITSR devient alors facile grâce à l'utilisation de la fonction de transfert basée sur un signal sinusoïdal. Le calcul de la performance d'un réfrigérateur d'essai a ensuite montré que cette analyse est précise. Une corrélation empirique pour un coefficient de correction $\mathrm{r}$ dans la chambre d'expansion a été dérivée afin d'obtenir de meilleurs résultats. Cette étude a montré qu'une théorie d'un système linéaire ou une approche par dynamique du système peut être appliquée à la conception d'un ITSR. (C) 2000 Elsevier Science Ltd and IIR. All rights reserved. 


\begin{tabular}{|c|c|c|c|}
\hline \multirow{2}{*}{\multicolumn{2}{|c|}{ Nomenclature }} & \multicolumn{2}{|c|}{ Greek letters } \\
\hline & & $\varepsilon$ & regenerator porosity, dimensionless \\
\hline$a_{\mathrm{dp}}$ & gain of $G_{\mathrm{dp}}(s)$ & $\tau$ & time constant (s) \\
\hline$a_{\mathrm{ep}}$ & gain of $G_{\mathrm{ep}}(s)$ & $\omega$ & angular frequency $(=2 \pi f)\left(\mathrm{rad} \mathrm{s}^{-1}\right)$ \\
\hline$A$ & area $\left(\mathrm{m}^{2}\right)$ & $\rho$ & density $\left(\mathrm{kg} \mathrm{m}^{-3}\right)$ \\
\hline \multirow{2}{*}{$C_{\mathrm{p}}$} & flow capacitance $\left(\mathrm{m}^{3} \mathrm{~kg} \mathrm{~kJ}^{-1}\right)$ & $\theta$ & displacer leading angle to piston, deg \\
\hline & $\begin{array}{l}\text { specific heat at constant pressure }\left(\mathrm{kJ} \mathrm{kg}^{-1}\right. \\
\left.\mathrm{K}^{-1}\right)\end{array}$ & \multicolumn{2}{|c|}{ Subscripts } \\
\hline$C_{\mathrm{v}}$ & $\begin{array}{l}\text { specific heat at constant volume }\left(\mathrm{kJ} \mathrm{kg}^{-1}\right. \\
\left.\mathrm{K}^{-1}\right)\end{array}$ & $\mathrm{c}$ & $\begin{array}{l}\text { compression chamber; characteristic impe- } \\
\text { dance; cold end }\end{array}$ \\
\hline$h$ & $\begin{array}{l}\text { convection heat transfer coefficient }\left(\mathrm{W} \mathrm{m}^{-2}\right. \\
\left.\mathrm{K}^{-1}\right)\end{array}$ & $\begin{array}{l}\text { ce } \\
d\end{array}$ & $\begin{array}{l}\text { cold end } \\
\text { displacer }\end{array}$ \\
\hline$d$ & diameter (m) & $\mathrm{e}$ & expansion space \\
\hline$f$ & frequency $(\mathrm{Hz})$ & $\mathrm{f}$ & gas; fluid; flow \\
\hline$k$ & thermal conductivity $\left(\mathrm{W} \mathrm{m}^{-1} \mathrm{~K}^{-1}\right.$ ) & $\mathrm{g}$ & gas \\
\hline$L$ & length (m) & $\mathrm{h}$ & hot end; hydraulic \\
\hline$m$ & mass flow rate $\left(\mathrm{kg} \mathrm{s}^{-1}\right)$ & $\mathrm{H}$ & hot end of the regenerator \\
\hline$R$ & gas constant $\left(\mathrm{kJ} \mathrm{kg}^{-1} \mathrm{~K}^{-1}\right)$ & $\mathrm{i}$ & inlet \\
\hline $\operatorname{Re}$ & Reynolds number, dimensionless & $\mathrm{L}$ & cold end \\
\hline$p$ & pressure, $\mathrm{Pa}\left(\mathrm{N} \mathrm{m}^{-2}\right)$ & $\mathrm{m}$ & mean; regenerator matrix \\
\hline$P_{\mathrm{ch}}$ & charge pressure, $\mathrm{Pa}\left(\mathrm{N} \mathrm{m}^{-2}\right)$ & o & outlet; equilibrium point; amplitude \\
\hline$Q_{\text {net }}$ & net cooling capacity (W) & $\mathrm{p}$ & piston \\
\hline$s$ & Laplace variable, complex & $\mathrm{r}$ & regenerator \\
\hline$T$ & temperature $(\mathrm{K})$ & $\mathrm{s}$ & solid material \\
\hline$t$ & time $(\mathrm{s})$ & $\mathrm{t}$ & gas passage \\
\hline$V$ & volume $\left(\mathrm{m}^{3}\right)$ & $\mathrm{w}$ & warm space; cylinder wall \\
\hline$x$ & distance $(\mathrm{m})$ & & \\
\hline \multirow[t]{2}{*}{$\mathrm{X}$} & displacement $(\mathrm{m})$ & \multicolumn{2}{|c|}{ Superscripts } \\
\hline & & $\sim$ & perturbed value \\
\hline
\end{tabular}

\section{Introduction}

An integral-type Stirling refrigerator (ITSR) comprises a compressor and a cold finger that are connected by a gas passage. The cold finger contains a moving regenerator/displacer, a cylinder, and an expansion space as shown in Fig. 1. Both the piston and the displacer motions are driven by a crank-shaft mechanism with a fixed phase angle between them. An electric motor drives the piston and hence the displacer such that the refrigerator operates approximately in a Stirling cycle. The physical processes involved in an ITSR includes thermodynamics, heat transfer of porous medium in the regenerator, gas transport in connecting tubes, tribology for the friction of piston and displacer motion. In addition, all the processes are at unsteady or cyclically-steady state. The thermal analysis of an ITSR is thus quite complicated.

Considerable work has been done by many researchers on the cycle analysis of the Stirling machine. The analysis basically utilizes the principle of thermodynamics and the conservation laws for mass, momentum and energy. The analysis is classified into two categories by
Organ [1], engineering thermodynamics approach and flow-field approach. In either approach, a numerical calculation using the finite difference method is sometimes employed to calculate the cycle performance and the form of the solution is mostly for a single operating point in the performance envelope of a specific machine. A performance map for a specific machine is hardly obtained for the selection of an optimum operating condition.

Urieli and Berchowitz [2] treated a free-piston Stirling machine as a generalized single degree of freedom system (damped mass-spring system in mechanics) and derived the general relations for piston-displacer amplitude ratio and phase angle in terms of operating frequency. In order to carry out the cycle performance calculation, Urieli and Berchowitz [2] further used the closed-form solution of the isothermal analysis for the working gas pressure as a function of compression and expansion volume. The relations of piston-displacer amplitude ratio and phase angle for a specific machine were derived and used in the cycle performance calculation. Since the isothermal model is an ideal model, the analysis of Urieli and Berchowitz [2] for a free-piston Stirling machine will be inaccurate. 


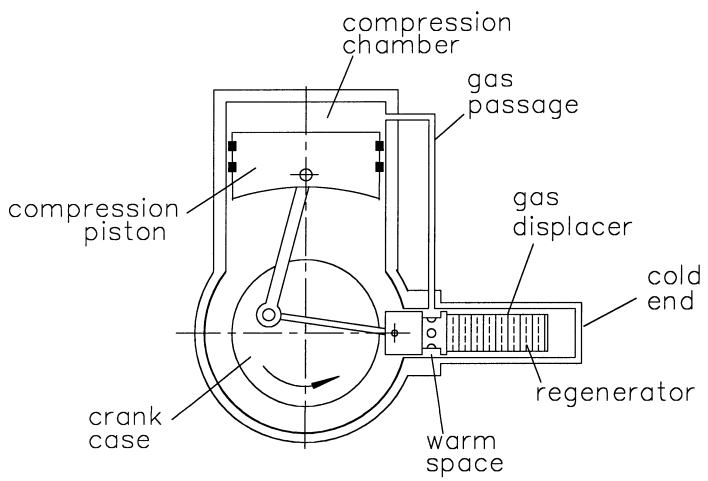

COMPRESSOR COLD FINGER

Fig. 1. Schematic diagram of an integral-type Stirling refrigerator.

Fig. 1. Schéma d'un réfrigérateur Stirling de type intégré.

For the analysis of an ITSR, a nodal model based on numerical computation scheme has been developed [3]. Several commercial software packages are available. However, the computation suffers easily from numerical problem and the accuracy in design is not known. In the present study, we intend to derive a model for the performance analysis of an ITSR that is different from the conventional approach in concept. A closed-form solution is obtained in transfer-function form and from which the performance of an ITSR is easily calculated.

Since an electric motor drives the piston and the displacer in sinusoidal motion approximately, a cyclicallysteady state operation very close to sinusoidal is obtained in an ITSR. Every component of the refrigerator is thus subject to a sinusoidal signal and generates a sinusoidal output just like the frequency response of a dynamical system, from the point of view of system dynamics. A dynamics model can then be derived to describe the input/output relation of each component using the governing equations based on the conservation laws for mass, momentum and energy and the principle of thermodynamics. A linear system dynamics model can be further derived in conjunction with linearization and approximations. A system dynamics model and an equivalent system block diagram or equivalent circuit can then be used to represent the dynamics behavior of each component. Connecting the analogous circuits of all the components together will lead to a network representing the operation of the refrigerator.

Huang and $\mathrm{Lu}$ [4] derived two transfer functions for the split-type free-displacer Stirling refrigerator (STFSR). In the present study, we derived a transfer-function model of the ITSR for the system performance analysis.

The major difference between ITSR and STFSR is the driving mechanism of the displacer. The displacer of an
ITSR is directly driven by a motor through a mechanism such as a crank-shaft mechanism. The displacer has a fixed stroke and a fixed phase angle with respect to the piston motion. For a STFSR, the displacer is driven by the fluid force or gaseous pressure which is indirectly induced by the piston motion. The stroke is thus variable and depends upon the operating conditions.

In modeling the ITSR by using a system dynamics approach, the piston displacement is the system input. The integral of the gas pressure in the expansion space with respect to the displacer motion is the gross refrigerating power that the refrigerator can obtain. The expansion-space pressure is, thus, the system output. That is, the refrigerator can be treated as a dynamical system with the piston displacement $X_{\mathrm{p}}$ as the system input and the gas pressure in the expansion space $p_{\mathrm{e}}$ as the system output. A transfer function representing the performance of the refrigerator can then be derived, from which the system performance can be easily evaluated at various operating points.

\section{Dynamics model of components}

Assuming that the working fluid is an ideal gas, we obtain the dynamics models of each component of an ITSR which are summarized as follows.

\subsection{Compression chamber}

Assuming an isothermal compression with a constant gas temperature $T_{\mathrm{c}}$ and no gas bypass between the piston and the cylinder, we obtain a dynamics model:

$\dot{m}_{\mathrm{p}}(s) \equiv \frac{s p_{\mathrm{o}} A_{\mathrm{p}}}{R T_{\mathrm{c}}} \tilde{X}_{\mathrm{p}}(s)=\dot{m}_{\mathrm{c}}(s)+\frac{\tilde{p}_{\mathrm{c}}(s)}{1 /\left(s C_{\mathrm{c}}\right)}$

where $C_{\mathrm{c}}=V_{\mathrm{co}} / R T_{\mathrm{c}}$ is the capacitance of the compression chamber. Here, $\dot{m}_{\mathrm{p}}(s)$ acts as a current source representing the available or gross mass flowrate generated by the piston motion; $\dot{m}_{\mathrm{c}}$ is the mass flowrate out of the compressor; $p_{\mathrm{c}}$ is the gas pressure inside the compression chamber; $\mathrm{V}_{\mathrm{c}}(\mathrm{t})=\mathrm{V}_{\text {co }}-\mathrm{A}_{\mathrm{p}} \mathrm{X}_{\mathrm{p}}(\mathrm{t}) ; \mathrm{V}_{\mathrm{co}}$ is the volume of the compression chamber for the piston at the equilibrium position; $\mathrm{X}_{\mathrm{p}}(\mathrm{t})$ is the piston displacement measured from the midpoint of the piston motion toward the top dead end; $A_{p}$ is the cross-section area of the piston.

\subsection{Gas passage}

The gas passage links the compressor and the cold finger. Following the same treatment of Huang and $\mathrm{Lu}$ [4] for a connecting tube (assuming an isothermal process with a constant temperature $\mathrm{T}_{\mathrm{t}}$ ), we obtain a 1-D dynamics model of the passage: 


$$
\begin{aligned}
{\left[\begin{array}{c}
\dot{m}_{\mathrm{to}}(s) \\
\tilde{p}_{\mathrm{to}}(s)
\end{array}\right]=} & {\left[\begin{array}{cc}
\cosh \left(\Gamma_{\mathrm{t}} L_{\mathrm{t}}\right) & -\frac{1}{Z_{\mathrm{ct}}} \sinh \left(\Gamma_{\mathrm{t}} L_{\mathrm{t}}\right) \\
-Z_{\mathrm{ct}} \sinh \left(\Gamma_{\mathrm{t}} L_{\mathrm{t}}\right) & \cosh \left(\Gamma_{\mathrm{t}} L_{\mathrm{t}}\right)
\end{array}\right] } \\
& \times\left[\begin{array}{c}
\dot{m}_{\mathrm{ti}}(s) \\
\tilde{p}_{\mathrm{ti}}(s)
\end{array}\right]
\end{aligned}
$$

where $\Gamma_{\mathrm{t}}=\sqrt{Z_{\mathrm{t}} Y_{\mathrm{t}}}$ and $Z_{\mathrm{ct}}=\sqrt{Z_{\mathrm{t}} / Y_{\mathrm{t}}}$ are the propagation constant and the characteristic impedance of the passage, respectively; $Z_{\mathrm{t}}=R_{\mathrm{Ft}}+s L_{\mathrm{Ft}}=$ series impedance and $Y_{\mathrm{t}}=s C_{\mathrm{Ft}}=$ shunt admittance;

$\Gamma_{\mathrm{t}}=\sqrt{s C_{\mathrm{Ft}}\left(R_{\mathrm{Ft}}+s L_{\mathrm{Ft}}\right)} ; Z_{\mathrm{ct}}=\frac{\Gamma_{\mathrm{t}}}{s C_{\mathrm{Ft}}}$

where $C_{\mathrm{Ft}}, L_{\mathrm{Ft}}$ and $R_{\mathrm{Ft}}$ are the flow capacitance, flow inductance, and flow resistance per unit passage length, respectively, which are defined as

$C_{\mathrm{Ft}}=\frac{A_{\mathrm{t}}}{R T_{\mathrm{t}}} ; L_{\mathrm{Ft}}=\frac{1}{A_{\mathrm{t}}} ; R_{\mathrm{Ft}}=\frac{\kappa}{A_{\mathrm{t}}}$

where

$\kappa=0.1556\left(\rho_{\mathrm{t}} w_{\max } d_{\mathrm{t}} / \mu\right)^{-0.201}\left(w_{\max } / d_{\mathrm{h}}\right)$,

$A_{\mathrm{t}}$ is the cross-sectional area of the passage; $w_{\max }$ is the peak velocity of the oscillating flow in the passage; $d_{\mathrm{t}}$ is the hydraulic diameter of the passage. $\kappa$ is considered to be a constant during the modeling, but should be adjusted by numerical iteration during the computation [4] to give a correct value for the corresponding mass flow $w_{\max }$.

\subsection{Warm space}

The gas in the warm space is assumed to be wellmixed at an uniform temperature. Similar to the compression chamber, a linearly perturbed model can be derived from mass continuity Eq. (4):

$\dot{m}_{\mathrm{wi}}(s)=\frac{s p_{\mathrm{o}} A_{\mathrm{dw}}}{R T_{\mathrm{w}}} X_{\mathrm{d}}(s)+\dot{m}_{\mathrm{wo}}(s)+\frac{\tilde{p}_{\mathrm{w}}(s)}{1 /\left(s C_{\mathrm{w}}\right)}$

where $C_{\mathrm{w}}=V_{\text {wo }} /\left(R T_{\mathrm{w}}\right)$. The first term in the right-hand side of Eq. (6) is the mass flowrate induced by the displacer motion, which is analogous to an electric current source; the third term represents the flow capacitance effect of the warm space.

\subsection{Regenerator}

The regenerator is an energy-storage element made from packed wire screens. Assuming 1-D flow, no axial conduction and constant properties, Huang and Lu $[4,5]$ obtained the dynamics model of the regenerator: $\left[\begin{array}{c}\dot{m}_{\mathrm{ro}}(s) \\ \tilde{p}_{\mathrm{ro}}(s)\end{array}\right]=R(s) \times\left[\begin{array}{c}\dot{m}_{\mathrm{ri}}(s) \\ \tilde{p}_{\mathrm{ri}}(s)\end{array}\right]$

where

$R(s)=\left[\begin{array}{cc}R_{\mathrm{mm}}(s) & R_{\mathrm{mp}}(s) \\ R_{\mathrm{pm}}(s) & R_{\mathrm{pp}}(s)\end{array}\right]$

$R_{\mathrm{mm}}(s)=R_{\mathrm{pp}}(s)=\cosh \left[\Gamma_{\mathrm{r}}(s) L_{\mathrm{r}}\right]$

$R_{\mathrm{mp}}(s)=-\frac{\sinh \left[\Gamma_{\mathrm{r}}(s) L_{\mathrm{r}}\right]}{Z_{\mathrm{cr}}(s)}$

$R_{\mathrm{pm}}(s)=-Z_{\mathrm{cr}}(s) \sinh \left[\Gamma_{\mathrm{r}}(s) L_{\mathrm{r}}\right]$

where $\Gamma_{\mathrm{r}}=\sqrt{Z_{\mathrm{r}} Y_{\mathrm{r}}}$ and $Z_{\mathrm{cr}}=\sqrt{Z_{\mathrm{r}} / Y_{\mathrm{r}}}$ are the propagation constant and the characteristic impedance of the regenerator, respectively; $Z_{\mathrm{r}}=R_{\mathrm{Fr}}+s L_{\mathrm{Fr}}=$ series impedance and $Y_{\mathrm{r}}=s C_{\mathrm{Fr}}=$ shunt admittance;

$\Gamma_{\mathrm{r}}=\sqrt{s C_{\mathrm{FTr}}\left(R_{\mathrm{Fr}}+s L_{\mathrm{Fr}}\right)} ; Z_{\mathrm{cr}}=\frac{\Gamma_{\mathrm{r}}}{s C_{\mathrm{FTr}}}$

where $C_{\mathrm{FTr}}$ is the regenerator flow capacitance due to pressure change and time responses of gas and matrix:

$C_{\mathrm{FTr}}=C_{\mathrm{Fr}} \frac{1+\tau_{\mathrm{sr}} /\left[\tau_{\mathrm{gr}}\left(1+s \tau_{\mathrm{sr}}\right)\right]}{\gamma+\tau_{\mathrm{sr}} /\left[\tau_{\mathrm{gr}}\left(1+s \tau_{\mathrm{sr}}\right)\right]}$

where $\gamma=C_{\mathrm{p}} / C_{\mathrm{v}} ; C_{\mathrm{Fr}}$ and $C_{\mathrm{Tr}}$ are the flow capacitance per unit length due to pressure and temperature changes, respectively; $L_{\mathrm{Fr}}$ and $R_{\mathrm{Fr}}$ are flow inductance, and flow resistance per unit length, respectively. They are defined as

$C_{\mathrm{Fr}}=\frac{A_{\mathrm{fr}}}{R T_{\mathrm{rm}}} ; C_{\mathrm{Tr}}=\frac{p_{\mathrm{rm}} A_{\mathrm{fr}}}{R T_{\mathrm{rm}}^{2}} ; L_{\mathrm{Ft}}=\frac{1}{A_{\mathrm{fr}}} ; R_{\mathrm{Fr}}=\frac{\bar{\alpha} \varepsilon v}{A_{\mathrm{fr}}}$

where

$\bar{\alpha}=\alpha+\left(\beta / d_{\mathrm{h}}\right) \varepsilon \mathrm{Re}_{\mathrm{h}} ; \alpha=175 /\left(2 \varepsilon d_{\mathrm{h}}^{2}\right) ; \beta=1.6 /\left(2 \varepsilon^{2} d_{\mathrm{h}}\right) ;$

$d_{\mathrm{h}}=\varepsilon d_{\mathrm{m}} /(1-\varepsilon) ; h=0.33\left(k_{\mathrm{f}} / d_{\mathrm{h}}\right) \mathrm{Re}_{\mathrm{h}}^{0.67}$

$\tau_{\mathrm{gr}}=\frac{p_{\mathrm{rm}} \varepsilon V_{\mathrm{o}} C_{\mathrm{v}}}{R T_{\mathrm{rm}} h A_{\mathrm{HT}}} ; \tau_{\mathrm{sr}}=\frac{\rho_{\mathrm{s}}(1-\varepsilon) V_{\mathrm{o}} C_{\mathrm{s}}}{h A_{\mathrm{HT}}}$

$A_{\mathrm{HT}}$ is the surface area of the regenerator $=$ $4 V_{\mathrm{o}}(1-\varepsilon) / d_{\mathrm{m}} ; \mathrm{Re}_{\mathrm{h}}$ is the Reynolds number based on hydraulic diameter $d_{\mathrm{h}} ; k_{\mathrm{f}}$ is the thermal conductivity of the gas.

Eq. (7) represents the dynamics model of the regenerator in terms of the pressure and mass flowrate that are derived from the continuity and momentum equations. The gas temperature at the cold side of the regenerator is derived as [4] 


$$
\begin{aligned}
\tilde{T}_{\mathrm{fr}}\left(L_{\mathrm{r}}, s\right)= & -\frac{C_{\mathrm{Fr}}}{C_{\mathrm{Tr}}} \frac{\tau_{\mathrm{gr}}\left(1+s \tau_{\mathrm{sr}}\right)}{\tau_{\mathrm{sr}}} \tilde{p}_{\mathrm{ro}}(s) \\
& -\frac{\gamma}{C_{\mathrm{Tr}}} \frac{\tau_{\mathrm{gr}}\left(1+s \tau_{\mathrm{sr}}\right) \Gamma_{\mathrm{r}}(s)}{s \tau_{\mathrm{sr}} \sinh \left[\Gamma_{\mathrm{r}} L_{\mathrm{r}}\right]} \\
& \times\left[\dot{m}_{\mathrm{ro}}(s) \cosh \left(\Gamma_{\mathrm{r}} L_{\mathrm{r}}\right)-\dot{m}_{\mathrm{ri}}(s)\right] .
\end{aligned}
$$

\subsection{Displacer}

The displacer of an ITSR is driven by a crank-shaft mechanism (Fig. 1). The time functions for the displacer and piston motion are approximately sinusoidal. Therefore,

$X_{\mathrm{d}}(t)=X_{\mathrm{do}} \sin (\omega t+\theta)$

$X_{\mathrm{p}}(t)=X_{\mathrm{po}} \sin (\omega t)$

where $X_{\mathrm{do}}$ and $X_{\mathrm{po}}$ are the amplitudes of the displacer and the piston, respectively; $\theta$ is the phase lead of the displacer. Thus, a transfer function $G_{\mathrm{dp}}(s)$ for the displacer motion can be derived as

$G_{\mathrm{dp}}(s)=\frac{X_{\mathrm{d}}(s)}{X_{\mathrm{p}}(s)}=\frac{X_{\mathrm{do}}}{X_{\mathrm{po}}} \mathrm{e}^{s \theta}$

\subsection{Expansion space}

The expansion space is usually an empty space for the gas to expand and absorb heat from the environment. Huang and Lu [4] derived a dynamics model from the mass continuity equation. To take into account the gas bypass from the displacer clearance, we modify the flow capacitance $C_{\mathrm{e}}\left(=V_{\mathrm{eo}} / R T_{\mathrm{ee}}\right)$ with a correction coefficient $r$ and obtain the dynamics equation:

$\dot{m}_{\mathrm{c}}(s)=\frac{\tilde{p}_{\mathrm{e}}(s)}{1 /\left(r s C_{\mathrm{e}}\right)}-\frac{s p_{\mathrm{o}} A_{\mathrm{de}}}{R T_{\mathrm{ce}}} \tilde{X}_{\mathrm{d}}(s)$

The second term in the right-hand side of Eq. (15) is the mass flowrate induced by the displacer motion, which is analogous to a current source. The correction coefficient $r$ represents the gas bypass from the displacer clearance. The amount of gas bypass is related to the seal design, manufacturing process, material used and operating condition. The relation of $r$ can be determined empirically. $r=1$ represents no gas bypass in the expansion space.

\section{Analogous network of integral-type stirling refrigerator}

Combining the equivalent circuits or block diagrams of all the components according to the process of ITSR, we obtain the analogous network as shown in Fig. 2.

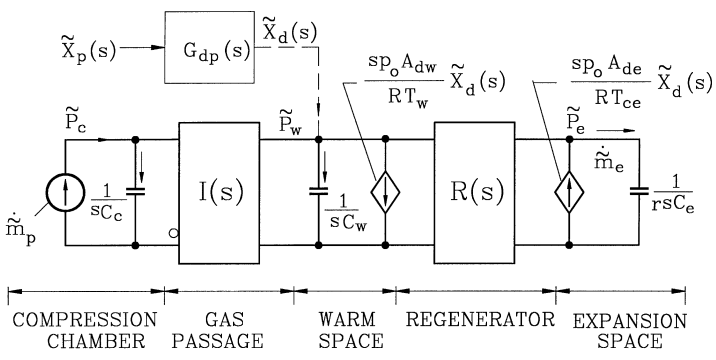

Fig. 2. Linear network of integral-type Stirling refrigerator.

Fig. 2. Réseau linéaire du réfrigérateur Stirling de type intégré.

The lower part of Fig. 2 is the fluid network in which mass flow is analogous to current and pressure is analogous to voltage. The fluid network depicts the gaseous flow propagation from the compressor to the expansion space. The upper part of Fig. 2 represents the displacer model which responds the piston motion by a phase angle $\theta$ and transfers the displacer displacement signal $\tilde{X}_{\mathrm{d}}$ to the fluid network. Since the displacer motion is fixed and follows the piston motion by a phase angle, we can solve the fluid network to find the gas flowrate and pressure at each component.

\section{Transfer function of integral-type stirling refrigerator}

We draw only block diagram in Fig. 2 for the gas passage and the regenerator since their dynamics models belong to distributed-parameter type. The transfer function of the ITSR is derived by combining the above equations:

$G_{\mathrm{ep}}(s)=\frac{\tilde{p}_{\mathrm{e}}(s)}{X_{\mathrm{p}}(s)}=G_{9}(s)+G_{10}(s) G_{\mathrm{dp}}(s)$

where

$$
\begin{aligned}
& G_{\mathrm{dp}}(s)=\frac{X_{\mathrm{d}}(s)}{X_{\mathrm{p}}(s)}=\frac{X_{\mathrm{do}}}{X_{\mathrm{po}}} \mathrm{e}^{s \theta} \\
& G_{10}(s)=\frac{G_{6}(s)-G_{7}(s) E_{\mathrm{md}}(s)}{G_{8}(s)+G_{7}(s) E_{\mathrm{me}}(s)} \\
& G_{9}(s)=\frac{1}{G_{8}(s)+G_{7}(s) E_{\mathrm{me}}(s)} \\
& G_{8}(s)=-G_{3}(s) R_{\mathrm{mp}}(s)+G_{5}(s) R_{\mathrm{mm}}(s) \\
& G_{7}(s)=G_{3}(s) R_{\mathrm{pp}}(s)-G_{5}(s) R_{\mathrm{pm}}(s) \\
& G_{6}(s)=G_{3}(s) W_{\mathrm{md}}(s) \\
& G_{5}(s)=G_{4}(s)-G_{3}(s) W_{\mathrm{mp}}(s) \\
& G_{4}(s)=-G_{1}(s) I_{\mathrm{mp}}(s)+G_{2}(s) I_{\mathrm{mm}}(s)
\end{aligned}
$$




$$
\begin{aligned}
& G_{3}(s)=G_{1}(s) I_{\mathrm{pp}}(s)-G_{2}(s) I_{\mathrm{pm}}(s) \\
& G_{2}(s)=\frac{C_{\mathrm{mc}}(s)}{C_{\mathrm{mp}}(s)} ; \quad G_{1}(s)=\frac{1}{C_{\mathrm{mp}}(s)} \\
& C_{\mathrm{mp}}(s)=\frac{s p_{\mathrm{o}} A_{\mathrm{p}}}{R T_{\mathrm{c}}} ; \quad C_{\mathrm{mc}}(s)=s C_{\mathrm{c}} \\
& W_{\mathrm{mp}}(s)=-\frac{s V_{\mathrm{wo}}}{R T_{\mathrm{w}}} ; W_{\mathrm{md}}(s)=-\frac{s p_{\mathrm{o}} A_{\mathrm{dw}}}{R T_{\mathrm{w}}} \\
& E_{\mathrm{me}}(s)=\frac{r s V_{\mathrm{eo}}}{R T_{\mathrm{ce}}} E_{\mathrm{md}}(s)=-\frac{s p_{\mathrm{o}} A_{\mathrm{de}}}{R T_{\mathrm{ce}}} \\
& I_{\mathrm{mm}}(s)=I_{\mathrm{pp}}(s)=\cosh \left[\Gamma_{\mathrm{t}}(s) L_{\mathrm{t}}\right] \\
& I_{\mathrm{mp}}(s)=-\frac{\sinh \left[\Gamma_{\mathrm{t}}(s) L_{\mathrm{t}}\right]}{Z_{\mathrm{ct}}(s)} ; I_{\mathrm{pm}}(s)=-Z_{\mathrm{ct}} \sinh \left[\Gamma_{\mathrm{t}}(s) L_{\mathrm{t}}\right]
\end{aligned}
$$

It is seen that the system input of an ITSR is the piston displacement $X_{\mathrm{p}}$ of the compressor. The system output is the expansion space pressure $p_{\mathrm{e}}$. The integral-type Stirling refrigerator thus belongs to a single-input-singleoutput (SISO) dynamical system.

\section{Performance calculation}

\subsection{Maximum available cooling capacity}

The maximum available cooling capacity of an ITSR can be evaluated by integrating the expansion space pressure $p_{\mathrm{e}}(t)\left[=\bar{p}_{\mathrm{e}}+\tilde{p}_{\mathrm{e}}(t)\right]$ with respect to volume $V_{\mathrm{e}}(t)$, where $V_{\mathrm{e}}(t)$ is related to the displacer displacement $X_{\mathrm{d}}(t)$. For a given piston and displacer motion, $X_{\mathrm{p}}(t)$ and $X_{\mathrm{d}}(t)$, according to the crank-shaft mechanism design, $\tilde{p}_{\mathrm{e}}(t)$ can be obtained from the inverse of the transfer function $G_{\text {ep }}(s)$, Eq. (16). The computation procedure is however quite complicated. A simplification is needed. Since the piston is driven by a crankshaft mechanism, the piston and the displacer motion as well as the induced pressure and mass flow waves inside the refrigerator approaches sinusoidal with the time functions of $X_{\mathrm{d}}(t)$ and $\tilde{p}_{\mathrm{e}}(t)$ expressed as

$\tilde{p}_{\mathrm{e}}(t)=p_{\mathrm{eo}} \sin \left(\theta+\phi_{\mathrm{e}}\right)$

$$
X_{\mathrm{d}}(t)=X_{\mathrm{do}} \sin \left(\theta+\phi_{\mathrm{d}}\right)
$$

where $p_{\text {eo }}$ and $X_{\text {do }}$ are the amplitudes of the expansion space pressure and the displacer, respectively; $\phi_{\mathrm{e}}$ and $\phi_{\mathrm{d}}$ are the phase lead angles of $p_{\mathrm{e}}(t)$ and $X_{\mathrm{d}}(t)$ with respect to the piston motion. The amplitude of the expansion space pressure can then be expressed as

$$
\begin{aligned}
& p_{\mathrm{eo}}=\left|G_{\mathrm{ep}}(j \omega)\right|\left|X_{\mathrm{p}}(j \omega)\right|=a_{\mathrm{ep}} X_{\mathrm{po}} \\
& X_{\mathrm{do}}=\left|G_{\mathrm{dp}}(j \omega)\right|\left|X_{\mathrm{p}}(j \omega)\right|=a_{\mathrm{dp}} X_{\mathrm{po}}
\end{aligned}
$$

The maximum cooling capacity $Q_{\max }$ thus can be computed simply from the gains of the frequency response functions $G_{\mathrm{ep}}(j \omega)$ and $G_{\mathrm{dp}}(j \omega)$, i.e. $a_{\mathrm{ep}}$ and $a_{\mathrm{dp}}$, and the phase angles of $X_{\mathrm{d}}(t)$ and $p_{\mathrm{e}}(t)$, i.e. $\phi_{\mathrm{e}}$ and $\phi_{\mathrm{d}}$ :

$$
\begin{aligned}
Q_{\mathrm{max}}=f \int_{0}^{2 \pi} p_{\mathrm{e}} d V_{\mathrm{e}} & =f \pi p_{\mathrm{eo}} A_{\mathrm{de}} X_{\mathrm{do}} \sin \left(\phi_{\mathrm{d}}-\phi_{\mathrm{e}}\right) \\
& =f \pi a_{\mathrm{ep}} a_{\mathrm{dp}} X_{\mathrm{po}}^{2} A_{\mathrm{de}} \sin \left(\phi_{\mathrm{d}}-\phi_{\mathrm{e}}\right)
\end{aligned}
$$

where $A_{\mathrm{de}}$ is the cross-section area of the displacer.

\subsection{Net cooling capacity}

The net cooling capacity of an ITSR can be evaluated by subtracting the heat losses from the maximum available cooling capacity. There are three types of heat losses: namely, regenerator heat conduction loss $Q_{\text {cond }}$, regenerator enthalpy flow loss $Q_{\text {enth }}$, and displacer shuttle heat loss $Q_{\text {shutt }}$. Thus the net cooling capacity is

$Q_{\mathrm{L}}=Q_{\max }-Q_{\text {shutt }}-Q_{\text {cond }}-Q_{\text {enth }}$

where

$$
\begin{aligned}
Q_{\text {cond }} & =k_{\mathrm{eff}}\left(\pi D_{\mathrm{r}}^{2} / 4\right) \frac{T_{\mathrm{H}}-T_{\mathrm{L}}}{L_{\mathrm{r}}} \\
Q_{\mathrm{enth}} & =f \oint m_{\mathrm{ro}}(t) C_{\mathrm{p}} T_{\mathrm{fr}}\left(L_{\mathrm{r}}, t\right) d t \\
& =f \pi C_{\mathrm{p}}\left|\tilde{m}_{\mathrm{ro}}\right|\left|\tilde{T}_{\mathrm{fr}}\left(L_{\mathrm{r}}\right)\right| \cos \left(\phi_{\mathrm{m}}-\phi_{\mathrm{T}}\right)
\end{aligned}
$$

where $k_{\text {eff }}$ is the effective thermal conductivity of the regenerator; $D_{\mathrm{r}}$ is the regenerator diameter; $L_{\mathrm{r}}$ is the regenerator length; $T_{\mathrm{H}}$ and $T_{\mathrm{L}}$ are the temperature at the hot and cold ends of the regenerator; $\phi_{\mathrm{m}}$ and $\phi_{\mathrm{T}}$ are, respectively, the phases of $m_{\mathrm{ro}}(t)$ and $\tilde{T}_{\mathrm{fr}}\left(L_{\mathrm{r}}, t\right)$. $\tilde{T}_{\text {fr }}\left(L_{\mathrm{r}}, t\right)$ follows Eq. (13). The displacer/regenerator shuttle heat loss is evaluated from the relation of Baik and Chang [6]:

$Q_{\text {shutt }}=\frac{\pi D_{\mathrm{e}} S_{\mathrm{e}}}{4} 2 \pi f \quad k_{\mathrm{d}} \rho_{\mathrm{d}} C_{\mathrm{pd}} T_{10} \sin \phi$

where

$T_{10}=\Delta T_{\mathrm{d}} S_{\mathrm{e}} \frac{a_{2}}{\sqrt{\left(\frac{a_{1}+a_{2}}{\sqrt{2}}\right)^{2}+\left(\frac{a_{1}+a_{2}}{\sqrt{2}}+a_{1} a_{2}\right)^{2}}}$

$\phi=\tan ^{-1}\left(\frac{\frac{a_{1}+a_{2}}{\sqrt{2}}+a_{1} a_{2}}{\frac{a_{1}+a_{2}}{\sqrt{2}}}\right)$ 
$a_{1}=\frac{k_{\mathrm{d}}}{h} \sqrt{\frac{2 \pi f}{\alpha_{\mathrm{d}}}} ; \quad a_{2}=\frac{k_{\mathrm{w}}}{h} \sqrt{\frac{2 \pi f}{\alpha_{\mathrm{w}}}}$

where $D_{\mathrm{e}}$ is the displacer outside diameter; $S_{\mathrm{e}}$ is the displacer stroke; $k_{\mathrm{d}}$ is the displacer thermal conductivity; $k_{\mathrm{W}}$ is the cylinder wall thermal conductivity; $\rho_{\mathrm{d}}$ is the displacer density; $C_{\mathrm{pd}}$ is the displacer heat capacity; $\Delta T_{\mathrm{d}}$ is the axial temperature gradient of the displacer; $\alpha_{\mathrm{d}}$ and $\alpha_{\mathrm{w}}$ are the thermal diffusivity of the displacer and the cylinder wall; $h$ is the heat transfer coefficient.

The gas bypass loss at the clearance between the displacer and the cylinder wall is related to the seal design, manufacturing process, material used, and operating condition. A correction coefficient $r$ is introduced in the expansion space model, Eq. (15), to account for this effect.

\subsection{Refrigerator $C O P$}

The COP of the integral-type Stirling refrigerator can be evaluated by the relation:

$C O P=\frac{Q_{\mathrm{L}}}{W_{\text {comp }}}$

where

$W_{\text {comp }}=f \oint p_{\mathrm{c}} d \mathrm{~V}_{\mathrm{c}}$

For simplification, the compression work computed from the above equation does not take into account the motor efficiency.

\section{System design analysis and experimental verification}

The system design analysis of an ITSR can be carried out using the present model. For simplification, the following assumptions are made in the analysis:

1. Since the mixing is severe in the compression space, the gas temperature in the compressor can be assumed uniform. The gas temperature inside the gas passage is also assumed uniform since it is very short in ITSR. Therefore, the regenerator inlet temperature $T_{\text {ri }}$ approximates the gas temperature in the compression chamber $T_{\mathrm{c}}$ and in the passage $T_{\mathrm{t}}$, i.e. $T_{\mathrm{ri}} \approx T_{\mathrm{t}} \approx T_{\mathrm{c}}$.

2 . The gas temperature of the warm space is constant and equal to the outside wall surface temperature $T_{\mathrm{H}}$ and the regenerator inlet temperature $T_{\text {ri }}$. That is, $T_{\mathrm{w}} \approx T_{\mathrm{ri}} \approx T_{\mathrm{H}}$.

3. The gas temperature in the cold space (expansion space) $T_{\text {ce }}$ is approximately equal to the outside wall temperature of the cold end, $T_{\mathrm{L}}$. That is, $T_{\mathrm{ce}} \approx T_{\mathrm{L}}$.
4. The mean pressure $p_{\mathrm{o}}$ is equal to the charge pressure $P_{\mathrm{ch}}$.

5. The wall temperatures at the two ends of the regenerator, $T_{\mathrm{ri}}$ and $T_{\mathrm{ro}}$, are approximately constant. Thus, $T_{\mathrm{w}} \approx T_{\mathrm{ri}} \approx T_{\mathrm{t}} \approx T_{\mathrm{c}} ; T_{\mathrm{ro}} \approx T_{\mathrm{ce}} \approx T_{\mathrm{L}}$.

Table 1

Design specifications of a test refrigerator

Tableau 1

Spécifications pour la conception d'un réfrigérateur d'essai

\begin{tabular}{|c|c|c|}
\hline \multirow[t]{4}{*}{1.} & Compressor & \\
\hline & Piston diameter & $14 \mathrm{~mm}$ \\
\hline & Piston stroke & $2 \mathrm{~mm}$ \\
\hline & Connecting rod length & $17 \mathrm{~mm}$ \\
\hline \multirow[t]{3}{*}{2.} & Gas passage & \\
\hline & Length & $25 \mathrm{~mm}$ \\
\hline & Inside diameter & $1.5 \mathrm{~mm}$ \\
\hline \multirow[t]{2}{*}{3.} & Warm space & \\
\hline & Volume & 0.5 c.c. \\
\hline \multirow[t]{6}{*}{4.} & Regenerator & \\
\hline & Wire screen material & SS316 \\
\hline & Wire screen mesh no. & 500 \\
\hline & Wire screen length & $37 \mathrm{~mm}$ \\
\hline & Wire screen diameter & $4 \mathrm{~mm}$ \\
\hline & Number of screen disks & 740 \\
\hline \multirow[t]{4}{*}{5.} & Displacer & \\
\hline & Stroke & $2.0 \mathrm{~mm}$ \\
\hline & Connecting rod length & $20.6 \mathrm{~mm}$ \\
\hline & Diameter & $6.15 \mathrm{~mm}$ \\
\hline \multirow[t]{3}{*}{6.} & Expansion space & \\
\hline & Diameter & $6.15 \mathrm{~mm}$ \\
\hline & Dead space length & $1.5 \mathrm{~mm}$ \\
\hline \multirow[t]{5}{*}{7.} & Design-point operating conditions & \\
\hline & Charge pressure & $13.6 \mathrm{~kg} / \mathrm{cm}^{2}$ gage \\
\hline & Frequency & $35 \mathrm{~Hz}$ \\
\hline & Cold-end temperature & $80 \mathrm{~K}$ \\
\hline & Net cooling capacity & $0.2 \mathrm{~W}$ \\
\hline
\end{tabular}

Table 2

Measured and calculated cooling capacity at $P_{\mathrm{ch}}=13.6 \mathrm{~kg} / \mathrm{cm}^{2}$ gage; $\mathrm{f}=35 \mathrm{~Hz}$

Tableau 2

Puissance frigorifique mesurée et calculée sous des conditions $\mathbf{P}_{c h}$ $=13,6 \mathrm{~kg} / \mathrm{cm}^{2} ; f=35 \mathrm{~Hz}$

\begin{tabular}{lll}
\hline Cold-end temp $T_{\mathrm{L}}, K$ & \multicolumn{2}{l}{ Net cooling capacity $Q_{\mathrm{L}}, W$} \\
\cline { 2 - 3 } & Calculated & Measured \\
\hline 58 & 0.126 & 0 \\
69 & 0.152 & 0.100 \\
76 & 0.167 & 0.150 \\
82 & 0.180 & 0.200 \\
90 & 0.196 & 0.250 \\
\hline
\end{tabular}


Given the refrigerator dimensions, the material physical properties, the operating conditions $\left(T_{\mathrm{L}}, P_{\mathrm{ch}}, f\right.$, $\left.T_{\mathrm{c}}, T_{\mathrm{w}}\right)$, and the working fluid properties, we can carry out the system performance analysis using the present model. It takes several seconds for each run on PC586.

We carry out a performance calculation for a test refrigerator with design specifications listed in Table 1. High purity helium gas is used as the working fluid. The test refrigerator is designed to operate with $0.2 \mathrm{~W}$ cooling capacity at $35 \mathrm{~Hz}$ and $14.6 \mathrm{~kg} / \mathrm{cm}^{2}$ abs charge pressure.

Table 2 shows that the measured net cooling capacity is very close to the calculated value from the assumption

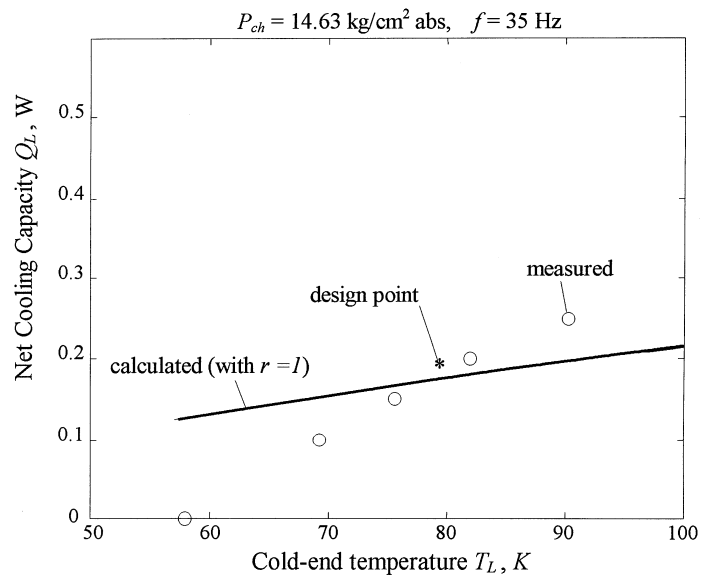

Fig. 3. Measured and calculated cooling capacity vs cold-end temperature.

Fig. 3. Puissance frigorifique mesurée et calculée en fonction de la température de l'extrémité froide.

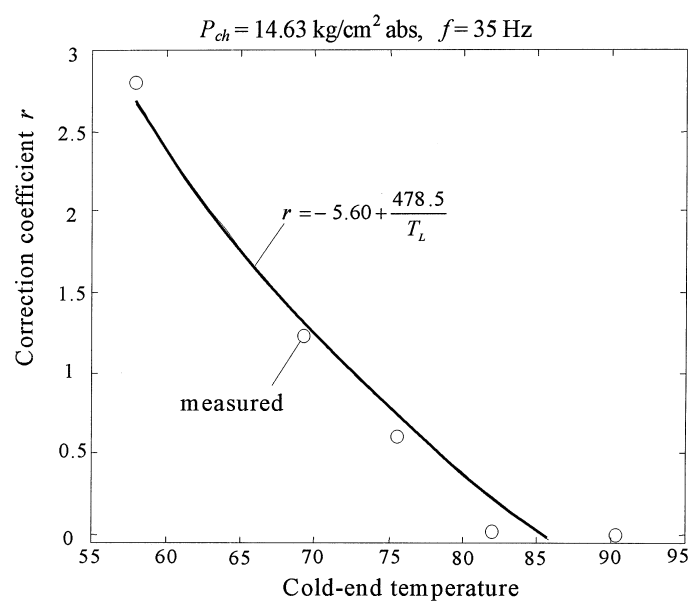

Fig. 4. Gas bypass correction coefficient.

Fig. 4. Coefficient de correction de la dérivation du gaz. of $r=1$ in Eq. (15), i.e. no gas bypass in the expansion space. It can be seen from Fig. 3 that the predicted value coincides with the measured value at the design point. The deviation between the measured and the calculated values however is larger at the off-design conditions. This may result from the gas bypass in the expansion space due to the variation of displacer clearance caused by the temperature change. The displacer casing of the test ITSR is made from a plastic material that may have a shrinkage different from the cylinder wall material (stainless steel) over different $\mathrm{T}_{\mathrm{L}}$.

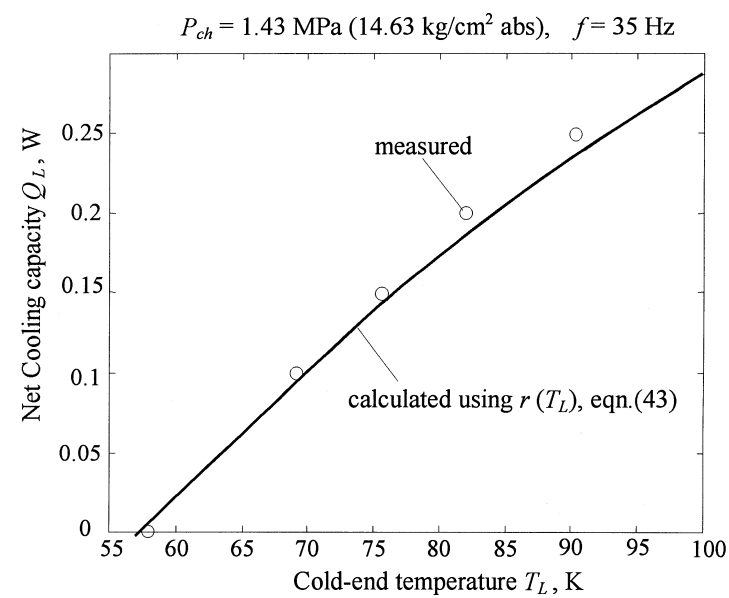

Fig. 5. Comparison of measured cooling capacity with calculated results.

Fig. 5. Comparaison de la puissance frigorifique mesurée et des résultats calculés.

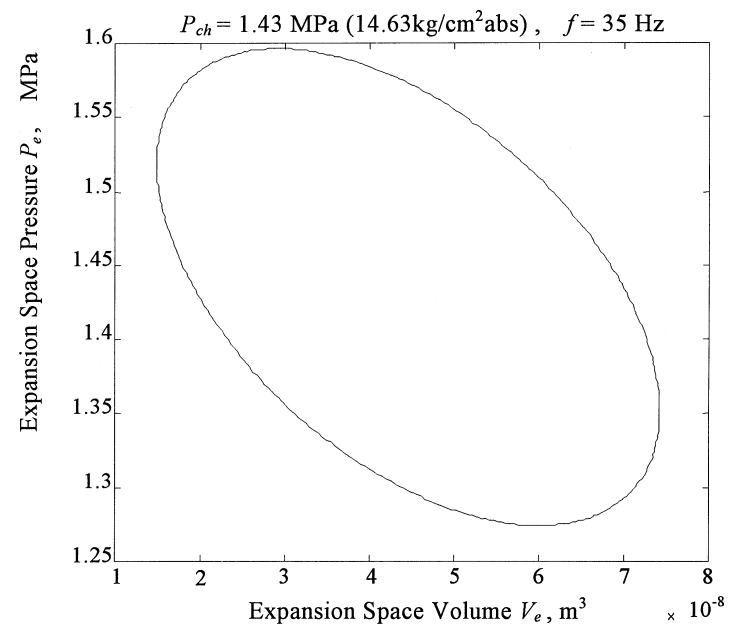

Fig. 6. Calculated expansion space PV diagram.

Fig. 6. Diagramme pression-volume de la chambre d'expansion. 
The correction coefficient $r$ is determined by adjusting its value so as to fit the calculated $\mathrm{Q}_{\mathrm{L}}$ to the measured $\mathrm{Q}_{\mathrm{L}}$. Fig. 4 shows the determined value of $r$. An empirical correlation is derived for $P_{\mathrm{ch}}=1.43 \mathrm{MPa}\left(14.63 \mathrm{~kg} / \mathrm{cm}^{2}\right)$ and $f=35 \mathrm{~Hz}$ :

$r=-5.60+\frac{478.5}{T_{\mathrm{L}}}$

The predicted net cooling capacity coincides with the test results, as shown in Fig. 5, if the correction coefficient relation, Eq. (43), was used. Figs. 6 and 7 are, respectively, the PV diagram and the COP of the refrigerator predicted from the present analysis. The correction coefficient $r$ may vary with the operating frequency, in addition to

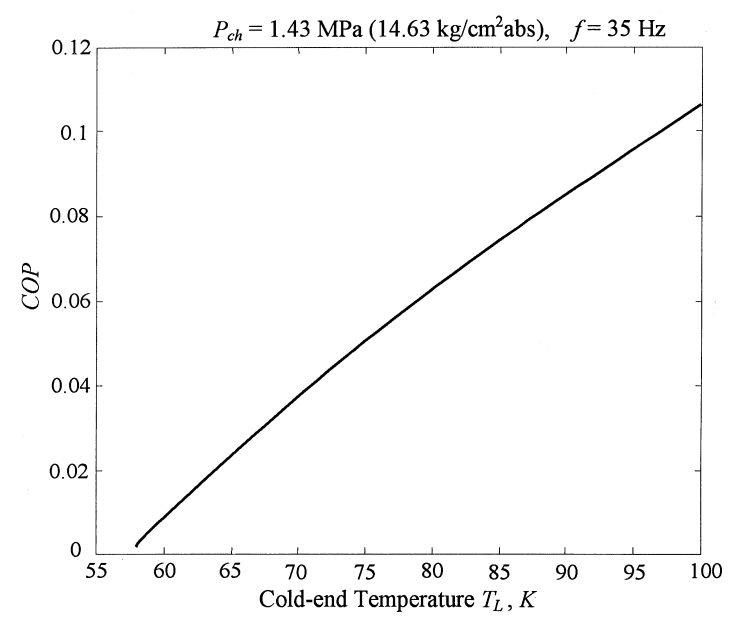

Fig. 7. Calculated COP vs cold-end temperature.

Fig. 7. COP calculé en fonction de la température de l'extrémité froide.

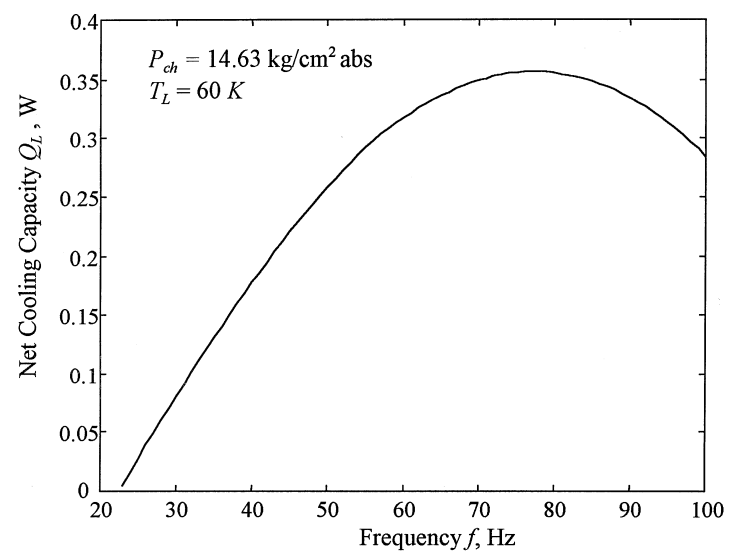

Fig. 8. Prediction of net cooling capacity variation with operating frequency.

Fig. 8. Prévision des variations de puissance frigorifique nette selon la fréquence de fonctionnement utilisée. the cold-end temperature. A more general empirical correlation of $r$ is also derived from the analysis of test data:

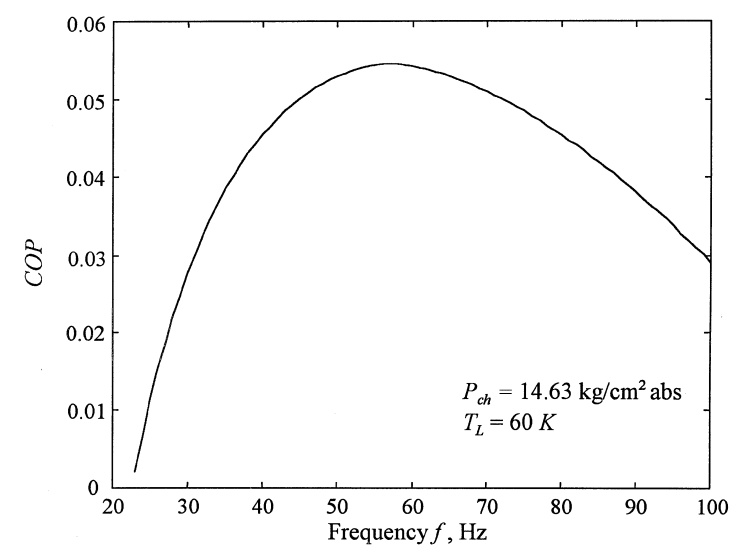

Fig. 9. Prediction of COP variation with operating frequency.

Fig. 9. Prévision de la variation du COP selon la fréquence de fonctionnement utilisée.

Table 3

Comparison of measured and calculated cold-end temperature at various operating conditions (all with $P_{\mathrm{ch}}=1.43 \mathrm{MPa}$ )

Tableau 3

Comparaison des températures d'extrémité froide mesurées et calculées sous diverses conditions de fonctionnement (dans tous les cas avec $\mathrm{P}_{c h}=1,43 \mathrm{MPa}$ )

\begin{tabular}{|c|c|c|c|c|}
\hline \multirow{2}{*}{$\begin{array}{l}\text { Net cooling } \\
\text { capacity } \\
Q_{\mathrm{L},} W\end{array}$} & \multirow[t]{2}{*}{$\begin{array}{l}\text { Frequency, } \\
\mathrm{Hz}\end{array}$} & \multicolumn{2}{|c|}{$\begin{array}{l}\text { Cold-end } \\
\text { temperature, } \mathrm{K}\end{array}$} & \multirow[t]{2}{*}{$\begin{array}{l}\text { Calculated- } \\
\text { measured, K }\end{array}$} \\
\hline & & Calculated & Measured & \\
\hline \multirow[t]{4}{*}{0} & 35 & 57.3 & 57.9 & -0.6 \\
\hline & 40 & 54.0 & 56.5 & -2.5 \\
\hline & 45 & 54.0 & 56.5 & -2.5 \\
\hline & 50 & 50.7 & 55.0 & -4.3 \\
\hline \multirow[t]{4}{*}{0.10} & 35 & 69.8 & 69.2 & 0.6 \\
\hline & 40 & 64.9 & 64.0 & 0.9 \\
\hline & 45 & 61.7 & 61.4 & 0.3 \\
\hline & 50 & 59.6 & 59.7 & -0.1 \\
\hline \multirow[t]{4}{*}{0.15} & 35 & 76.6 & 75.6 & 1.0 \\
\hline & 40 & 70.6 & 68.6 & 2.0 \\
\hline & 45 & 66.6 & 65.8 & 0.8 \\
\hline & 50 & 64.1 & 63.8 & 0.3 \\
\hline \multirow[t]{4}{*}{0.20} & 35 & 84.2 & 82.0 & 2.2 \\
\hline & 40 & 76.8 & 74.3 & 2.5 \\
\hline & 45 & 71.9 & 70.4 & 1.5 \\
\hline & 50 & 73.4 & 72.1 & 1.3 \\
\hline \multirow[t]{4}{*}{0.25} & 35 & 92.8 & 90.3 & 2.5 \\
\hline & 40 & 83.5 & 79.8 & 3.7 \\
\hline & 45 & 77.4 & 75.2 & 2.2 \\
\hline & 50 & 73.4 & 72.1 & 1.3 \\
\hline
\end{tabular}




$$
\begin{aligned}
r= & {\left[-5.988+\frac{478.5}{T_{\mathrm{L}}}\right] } \\
& \times\left(1.589-3.6211 \times 10^{-2} f+5.5041 \times 10^{-4} f^{2}\right)
\end{aligned}
$$

where $T_{\mathrm{L}}$ is in $\mathrm{K} ; f$ is in $H z$.

Table 3 shows the comparison between measured and calculated $T_{\mathrm{L}}$ of the test refrigerator. It is shown that all the deviations are within $\pm 5 K$, mostly within $\pm 3 K$.

\section{Discussion and conclusion}

The performance calculation of an ITSR may not be so difficult. If we look at the performance of an ITSR from the point of view of system dynamics, the modeling can be greatly simplified. It is shown in the present study that a transfer function can be derived to represent the system dynamics behavior of an ITSR and from which the thermal performance can be evaluated with sinusoidal signal assumption. The computation on PC586 just takes a few seconds for a design calculation. The performance calculation for a test refrigerator has shown that the analysis is accurate at the design point. An empirical correlation for the correction coefficient $r$ in the expansion space was also derived in the present study for better results at off-design conditions. A PCbased computer package was also developed in the present study so that engineer can easily use it for design purposes. The modeling can be improved furthermore by applying a better oscillating-flow heat transfer and frictional correlation for the regenerator and the gas passage, if they are available. It is also noticeable that the manufacturing quality and the material selected for the displacer, the regenerator, and the cylinder wall are crucial. Any moderate defect during manufacturing will cause the performance to deviate largely from the prediction. The correction coefficient $r$ reflects to some extent on this factor and the function would depend largely on individual overall engineering capability. Finally, it should be emphasized that the present study has demonstrated how a linear system theory or system dynamics approach can be applied to the design of an ITSR. This approach enables us to draw a performance map of a specific ITSR at various operating conditions and study the optimum design. The performance calculation follows the frequency-response analysis and presents the performance over all operating frequencies. Figs. 8 and 9 are the prediction of $\mathrm{Q}_{\mathrm{L}}$ and COP for the present test ITSR operated at $P_{\mathrm{ch}}=14.63 \mathrm{~kg} / \mathrm{cm}^{2}$ abs and $T_{\mathrm{L}}=60 \mathrm{~K}$. It is seen that an optimum operating frequency can be determined with respect to either the maximum net cooling capacity $\mathrm{Q}_{\mathrm{L}}$ or the maximum COP. If we repeated the same calculation of Figs. 8 and 9 for different $P_{\text {ch }}$ or $T_{\mathrm{L}}$, we can draw a performance map for a specific ITSR for design selection.

\section{Acknowledgements}

The present study was supported by the National Science Council, Taiwan, through the Grant No.NSC81-0401-E002-587, No.CS83-0210-D-002-011 and No.CS84-0210-D-002-027.

\section{References}

[1] Organ AJ. Thermodynamics and gas dynamics of the stirling cycle machine. Cambridge: Cambridge University Press, 1992 (chapter 4).

[2] Urieli I, Berchowitz DH. Stirling cycle engine analysis. Bristol, UK: Adam Hilger Ltd, 1984.

[3] Yuan SWK, Spradley IE, Yang PM, Nast TC. Computer simulation model for Lucas Stirling refrigerators. Cryogenics 1992;32:143-8.

[4] Huang BJ, Lu CW. Split-type free-displacer Stirling refrigerator design using linear network analysis. Cryogenics 1996;36:1005-17.

[5] Huang BJ, Lu CW. Linear network analysis of regenerator in a cyclic-fkiw system. Cryogenics 1995;35:203-7.

[6] Baik JH, Chang HM. An exact solution for shuttle heat transfer. Cryogenics 1995;35:9-13. 